\title{
COVID-19, Mental Health, and Religious Coping Among American Orthodox Jews
}

\author{
Steven Pirutinsky ${ }^{1}$ Aaron D. Cherniak ${ }^{2,3}$ - David H. Rosmarin ${ }^{4}$
}

Published online: 23 July 2020

(c) Springer Science+Business Media, LLC, part of Springer Nature 2020

\begin{abstract}
The COVID-19 pandemic presents potential mental health challenges, and the American Orthodox Jewish population has been particularly affected by the virus. The current study assessed the impact of the pandemic and explored the relationships between exposure, religiosity, and distress in a sample of $n=419$ American Orthodox Jews. Results indicated high levels of exposure, concern, and compliance with medical guidelines; however stress was generally low and we found evidence for positive impact. Direct exposure correlated with higher religiosity. Positive religious coping, intrinsic religiosity and trust in God strongly correlated with less stress and more positive impact, while negative religious coping and mistrust in God correlated with the inverse. While the study is limited by its design, findings highlight that for some, faith may promote resilience especially during crisis.
\end{abstract}

Keywords Jewish $\cdot$ Mental health $\cdot$ Crisis $\cdot$ Trauma $\cdot$ Coping

\section{Introduction}

Since its December 2019 outbreak, the novel coronavirus SARS-CoV-2 (or, colloquially, COVID-19) has spread rapidly into a deadly global pandemic. In addition to the severe threat it poses to people's physical health and lives, COVID-19 has overwhelmed governments and public health systems prompting them to adopt extraordinary measures including restricting people to their homes and closing the majority of business. Both the illness and its fallout present tremendous challenges to mental

Steven Pirutinsky

steven.pirutinsky2@touro.edu

1 Graduate School of Social Work, Touro College, 27 West 23rd Street, 5th Floor, New York, NY 10010, USA

2 Department of Psychology, Stockholm University, Stockholm, Sweden

3 Mental Health Department, Mayanei HaYeshua Medical Center, Bnei Brak, Israel

4 Harvard Medical School/McLean Hospital, Belmont, MA, USA 
health such as rising levels of symptoms of panic disorder, anxiety, depression, and posttraumatic stress (e.g., Qiu et al. 2020; Wang et al. 2020; McBride et al. 2020). Elevated risk has been reported among those with more direct exposure such as those who were infected, have family members who were infected, and health care workers (Simione and Gnagnarella 2020). In addition, groups considered at higher risk for severe illness due to COVID-19, including the elderly and individuals with serious underlying medical conditions, have shown increased risk for psychological difficulties (e.g., Vahia et al. 2020). The immediate access to mass media and social media reports regarding COVID-19 appear to exacerbate distress through vicarious traumatization ( $\mathrm{Li}$ et al. 2020). Amplifying these challenges are psychosocial factors such as substantial economic hardship, lockdown-type measures, and extended social isolation associated with the pandemic (Armitage and Nellums 2020; Torales et al. 2020). These patterns are widely noted in previous studies of mental health in various disaster contexts, however, the global scope of COVID-19- likely compounds these factors.

\section{COVID and the American Orthodox Jewish Community}

The American Orthodox Jewish population has been particularly affected by the COVID-19 pandemic as they are primarily based in large urban areas such as New York and New Jersey, which are some of the hardest hit regions of the US with high prevalence and widespread community transmission (Centers for Disease Control 2020). According to public health reports, Orthodox Jewish communities, especially those composed of tight-knit Hasidic groups, may have elevated COVID-19 mortality as compared to other ethnic or religious groups in the USA, and numerous influential religious leaders have died (Stack 2020). Public health initiatives, especially stay-at-home orders, may be particularly stressful to Orthodox communities as they are characterized by a collective communal, familial, and social culture that values interaction with others (Heilman 2000). In fact, social support proffered by faith communities is generally an important mediator of the association between religion and health—both mental (Koenig 2018) and physical (Koenig et al. 2012), and Orthodox Jews typically gather for communal prayer three times daily and gather regularly for communal events, religious holidays, life cycle occasions, and religious study. In addition, more traditional Orthodox communities may be particularly affected as they are composed of large families (Pirutinsky et al. 2015), many of whom experience low socioeconomic status (Pearson and Geronimus 2011) and have limited access to technology (Hack 2007), which has become uniquely important to daily life under social distancing conditions (Ho et al. 2020). Finally, beyond the direct impact on Jews' physical and mental health, conspiracy theories about COVID-19 have targeted Jews, echoing old libels related to past pandemics, and anti-Semitic incidents have increased 18\% since the outbreak (Kantor Center 2020; Heller 2020). 


\section{Religious Coping}

Decades of research shows that religious individuals use spirituality and religion to cope during times of stress (Ano and Vasconcelles 2005; Pargament 2001; Koenig 2018), and accordingly during the COVID-19 pandemic, interest in religion has soared. This is unsurprising given that religion is a key aspect of identity that people rely upon to cope (Aten et al. 2019) and that undergoes significant changes during and following mass societal trauma (Henrich et al. 2019), effects which can have long-lasting and even intergenerational effects (Bentzen 2019). However, the degree of the shift is unprecedented. For example, Bentzen (2020) noted that, by March, the number of Google searches of "prayer" had reached a record high for the 5 years for which relevant data are available, which greatly exceeds any explicitly religious event over that period. Rates correspond to the trajectory of the pandemic in different regions of the world, and the searches double for every 80,000 registered cases.

Why the turn to religion? First, religiosity may be a particularly powerful resource for mental health since it involves a framework of meaning-making associated with decreased psychological distress and a value-based pursuit of psychological well-being (Koenig et al. 2012; Rosmarin and Koenig 2020). Second, it also provides a source of attitudes and cognitions that can reframe negative events into less stressful frames (Jenkins and Pargament 1995), provides a source of social support (Lim and Putnam 2010), appears to increase self-control (McCullough and Willoughby 2009), enhances gratitude, and includes practices and behaviors such as prayer, study, and mindfulness that are linked to lower negative affect (Hackney and Sanders 2003). For example, positive beliefs about the Divine can engender trust in God, which is known to buffer against anxiety and sadness (Rosmarin et al. 2009a), and intrinsic religiosity involving valuing religion in of itself similarly seems to be a psychological support (Baker and Gorsuch 1982). Beyond this, religiosity generally involves an affective bond with an omnipresent and omniscient deity and research indicates that this attachment provides salutary effects on mental health (Granqvist 2020; Cherniak et al. 2020a; Pirutinsky et al. 2019). Furthermore, when used in the context of life stressors, religion can be a positive coping resource involving "the use of religious beliefs or behaviors to facilitate problem-solving to prevent or alleviate the negative emotional consequences of stressful life circumstances" (Koenig et al. 1998, p. 513). Positive religious coping has been associated with various favorable outcomes such as reduced depression and anxiety as well as increased psychological well-being both in the general population (Koenig 2018) and among Jews specifically (Rosmarin et al. 2009b).

On the other hand, religiosity can also have negative or harmful effects mental health when it involves negative affective attitudes regarding God, negative religious behaviors, and spiritual struggles (Pargament et al. 1998). In fact, disasters and other traumatic stressors appear particularly likely to prompt spiritual struggles, or conflicts over spiritual matters that generate distressing emotions (e.g., questions of theodicy; Exline and Rose 2013), which can lead to both growth and decline outcomes (Desai and Pargament 2015). This phenomenon has been termed, negative religious coping, and it involves religious beliefs or behaviors that exacerbate stress and has also been associated with unfavorable outcomes such as increased spiritual struggles 
and ensuing psychological distress both in the general population (Koenig 2018) and among Jews specifically (Pirutinsky et al. 2011). Similarly, mistrust in God, refers to negative belief about God (Rosmarin et al. 2011b), and has been associated with poorer mental health (Koenig 2018).

\section{Current Study}

The current study assessed the impact of the COVID-19 pandemic on the American Jewish community generally, and specifically explored the relationship between COVID-19 exposure, religiosity, and distress. We focused on three key religious variables that have previously been demonstrated to relate with mental health in the Jewish community: Intrinsic motivations for religiosity, positive/negative religious coping, and trust/mistrust in God (Pirutinsky and Rosmarin 2018; Rosmarin et al. 2017; Rosmarin et al. 2011a, b).

\section{Method}

\section{Participants and Procedure}

Using email lists and web sites of both Jewish organizations, social media, and snowball approaches (asking participants to inform others), we recruited participants for a "Research Study on Jewish Community Responses to COVID-19." Prospective participants were directed toward an anonymous online survey that included the study questionnaire, which assessed for demographics, COVID-19 risk factors, attitudes and behaviors, various facets of religion and spirituality, and several indices of mental health and well-being. The current study focused specifically on exposure to COVID-19, the impact of COVID-19, and correlations between religion and COVID-19 experiences. Data collection took place during the initial peak of the epidemic in the USA from March 29th 2020 until April 22nd 2020. By March 29th, there had been approximately 141,000 confirmed cases and 3420 deaths in the USA, counts which rose to 840,500 confirmed cases and 47,400 deaths by April 22nd (Johns Hopkins University and Medicine 2020). Worldwide, there had been approximately 638,100 confirmed cases and 30,000 deaths by March 29th, and 2,476,000 confirmed cases and 169,100 deaths by April 22nd (World Health Organization 2020). Of the 785 participants who had completed the survey at the time of our analyses, 419 met criteria for the current study as they resided in the USA and identified with an Orthodox Jewish religious affiliation. These participants were mostly female $(72 \%)$, ranged in age from 18 to $83(M=39.17, \mathrm{SD}=15.71)$, and most were married $(71 \%)$ or single/never-married $(22 \%)$. Reported ethnicity was largely white $(95 \%)$ and most were college educated (86\%). Specific Orthodox affiliations included Hassidic (5\%), Chabad/Lubavitch (3\%), Yeshiva Orthodox (43\%), Modern Orthodox (47\%), and Sephardic-Religious (2\%). Of these $280(67 \%)$ reported residing in the NY/NJ region, which is home to a large Orthodox Jewish population (Pew Research Center 2013). 


\section{Measures}

Exposure to COVID was measured using a series of three questions that asked if a participant themselves, someone close to them, or someone they had contact with has a confirmed or suspected infection with COVID-19. The negative impact of COVID was measured using a series of 12 questions that asked "To what extent has COVID-19 negatively impacted the following areas of your life:" and included items such as sleep, diet, work, relationships, faith, and character. Response choices included "not at all," "a little bit," "moderately," and "a lot." One additional item that asked about positive impact with the same response choices.

In terms of religion, we utilized three previously developed scales to assess key areas of religious experience. These included the three-item Intrinsic Religiosity subscale of the Duke Religion Index (Koenig and Büssing 2010; $\alpha=.81$ ), the 16-item Jewish Religious Coping scale (Rosmarin et al. 2009a) which yields two subscales to measure positive $(\alpha=.89)$, and negative religious coping $(\alpha=.76)$; and the six-item brief Trust $(\alpha=.94)$ and Mistrust $(\alpha=.74)$ in God scales (Rosmarin et al. 2011a, b). All of these scales have previously been utilized within the Orthodox Jewish community with adequate reliability and validity.

\section{Results}

\section{Exposure to COVID}

Levels of exposure to COVID-19 in the sample were relatively high, although within the range expected in highly affected areas such as New York and New Jersey in which COVID-19 has been declared as widespread at the time these data were collected (Centers for Disease Control 2020). Specifically, $48 \%$ of participants reported having contacted with an individual with confirmed or suspected COVID-19, 20\% reported having a confirmed or suspected infection themselves, and $58 \%$ reported that someone close to them had a confirmed or suspected infection. Consistent with these findings, those reporting no contact or infection indicated being somewhat $(48 \%)$ or very $(33 \%)$ concerned about becoming infected themselves, and being somewhat $(46 \%)$ or very $(48 \%)$ concerned that someone close to them will become infected. Participants in our sample reported high levels of secondary exposure to COVID-19, with the average participant reporting checking news media 2-4 times per day, checking social media 2-4 times per day, and engaging in one-on-one communication regarding COVID 2-4 times per day. In addition, the vast majority of participants (87\%) reported adhering "very much" to medical guidelines regarding COVID-19, such as social distancing, voluntary quarantine, and isolation/lockdown. 


\section{Predictors of COVID-19 Impact}

Despite high levels of infection and concern about becoming infected, participants reported that COVID-19 had little to moderate levels of impact on their lives across 13 specific domains $(M=2.34$, SD $=.59)$. However, dependent measures ANOVA suggested that there were significant differences between particular domains of impact $\left(F(11,4312)=88.36, p<.001, \eta^{2}=.18\right)$. We therefore examined mean levels for each individual impact item, which are displayed in Fig. 1 and indicate that participants reported significantly less than average impact on religious observance, faith in God, and their character (e.g., patience, trust), and significantly more impact on fitness, work, family, finances and emotions. Most participants reported at least some positive impact of COVID-19 (47\% "a little bit," 25\% "moderately," and 10\% "a lot), whereas only $18 \%$ reported "not at all."

Impact of COVID-19 was correlated to some degree with both direct and indirect exposure, but was more strongly associated with concern regarding possible exposure (Table 1). Specifically, concern regarding a possible infection was associated with negative impact in the majority of domains including sleep, diet, fitness, finances, family, relationships, character, strong emotions, and life satisfaction. A similar pattern of correlations was observed for secondary exposure via news media, social media, and one-on-one communications, which correlated with higher selfreported negative impact overall. Contact with an infected individual as well as self-reported infection was associated with less impact on diet and work but more impact on religious observance. Adherence to medical guidelines was not associated

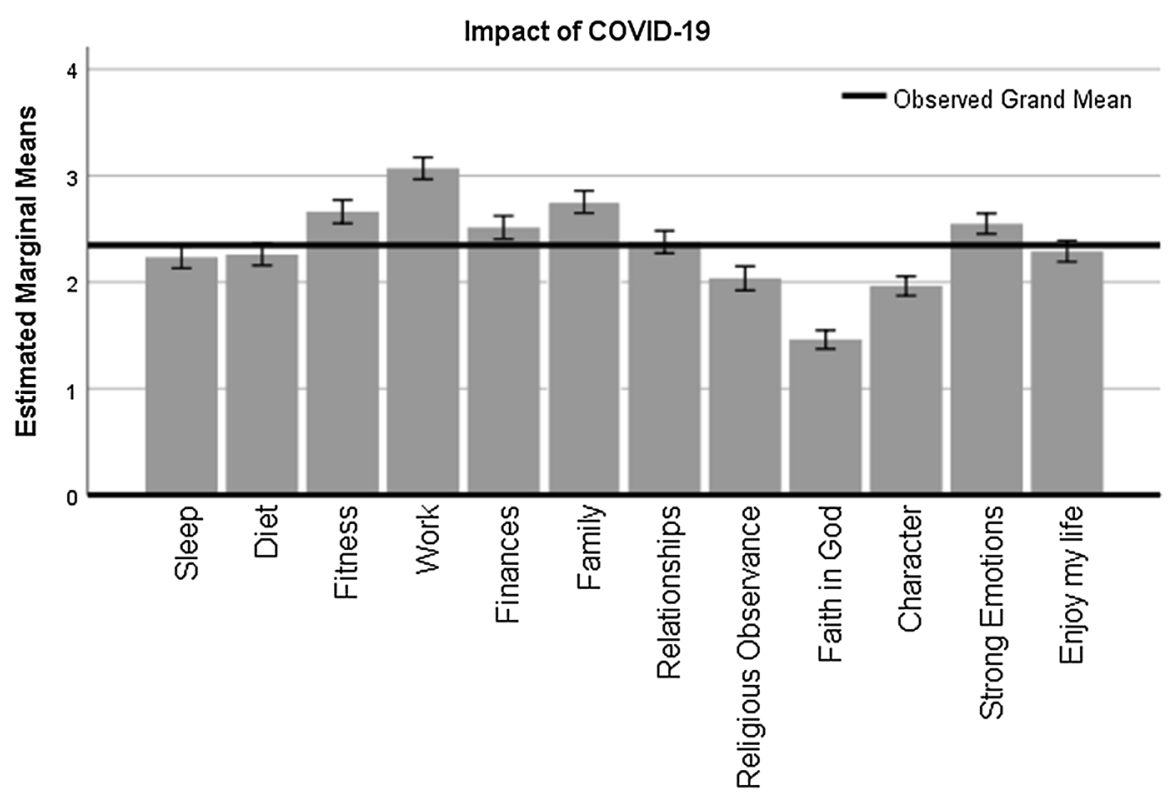

Fig. 1 Self-reported impact of COVID on various life domain of Orthodox Jews in the USA. Note: Error bars represent $95 \% \mathrm{CI}$ of the mean 


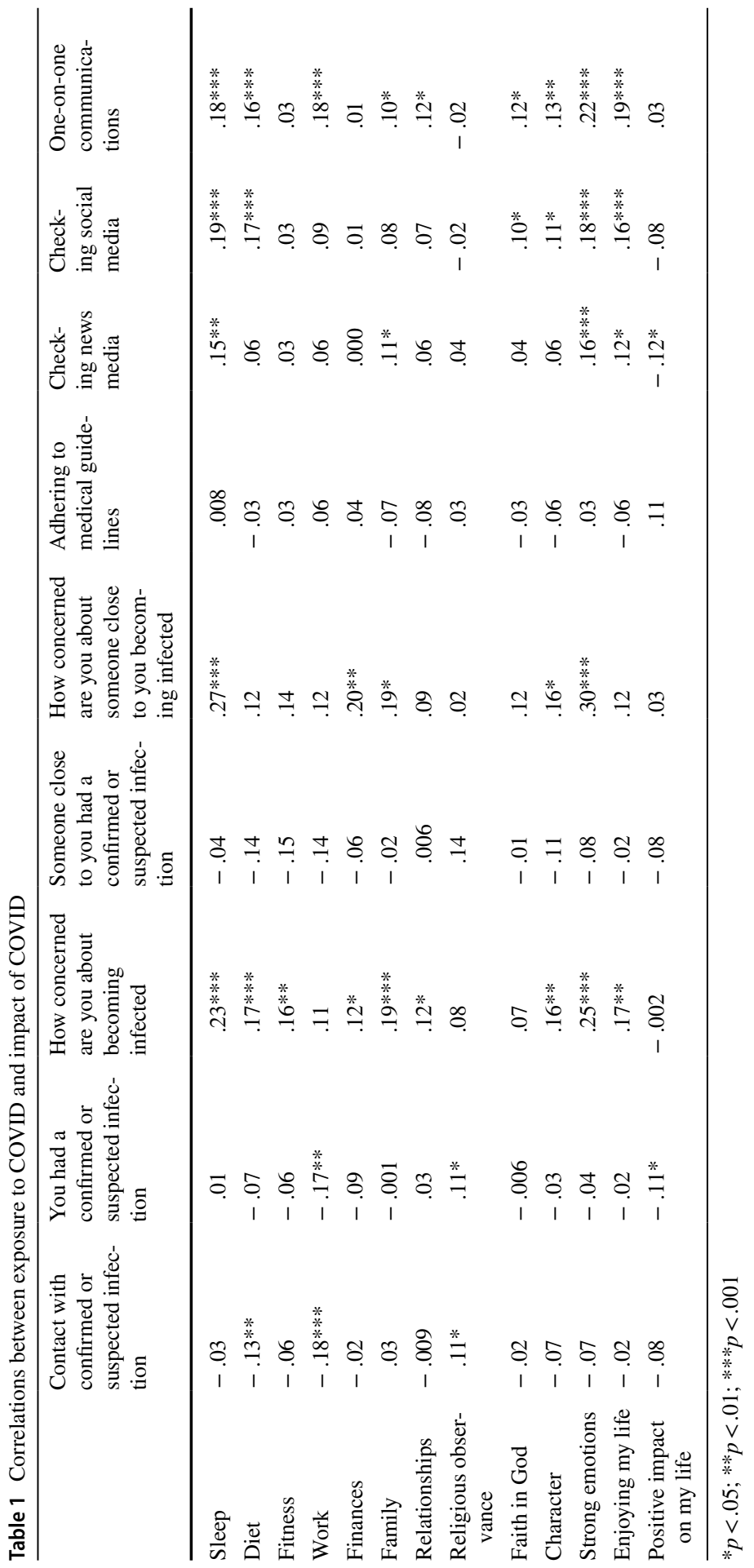


with any index of negative or positive self-reported impact. Participants reporting a confirmed or suspected infection surprisingly reported greater positive impact of COVID-19.

In terms of demographics, older age was associated with somewhat less negative impact on sleep $[r(343)=-.15, p=.005]$, diet $[r(342)=-.14, p=.008]$, work $[r(341)=-.12, p=.03]$, character $[r(340)=-.14, p=.008]$, emotions $[r(336)=-.15, p=.007]$, but with somewhat higher negative impact on religious observance $[r(343)=.17, p=.002]$. A larger number of household members was correlated with somewhat higher negative impact on work $[r(414)=.12, p=.01]$ but also slightly less negative impact on enjoying life $[r(416)=-.10, p=.046]$ and moderately more positive impact of COVID-19 $[r(416)=.25, p<.001]$. Higher education was related to slightly greater negative impact on work $[r(416)=.10$, $p=.04]$ and higher income was correlated with slightly less negative impact on finances $[r(406)=-.11, p=.04]$. There were some significant gender differences with females reporting higher negative impact than males in terms of sleep $[F(1$, $416)=10.12, p=.002]$, fitness $[F(1,416)=11.67, p=.001]$ and emotions $[F(1$, $402)=20.92, p<.001]$, while males reported higher negative impact on religious observance than females on religious observance $[F(1,417)=21.40, p<.001]$. Marital status was not a significant predictor of positive or negative impact of COVID-19.

\section{Religion and COVID}

Relationships between exposure to COVID-19 and religious variables were complex. Contact with a suspected or confirmed infection was correlated with higher intrinsic religiosity $\left[M_{\text {diff }}=.60, t(415)=2.86, p=.004, d=.28\right]$, higher trust in God $\left[M_{\text {diff }}=.72, t(392)=2.42, p=.02, d=.24\right]$, and lower mistrust in God $\left[M_{\text {diff }}=.42\right.$, $t(390)=2.60, p=.01, d=.26]$. Personal infection was similarly associated with higher intrinsic religiosity $\left[M_{\text {diff }}=.59, t(416)=2.26, p=.02, d=.22\right]$ and higher trust in $\operatorname{God}\left[M_{\mathrm{diff}}=.77, t(395)=2.07, p=.04, d=.21\right]$, as was "having someone close to you with a suspected or confirmed infection" [intrinsic religiosity: $M_{\text {diff }}=.58$, $t(416)=2.72, p=.007, d=.27$; higher trust in God: $M_{\text {diff }}=.60, t(395)=2.01$, $p=.046, d=.20]$. Concern with becoming infected did not significantly correlate with any religious variables, while concern about a loved one becoming infected moderately correlated with higher levels of negative religious coping $[r(172)=.21$, $p=.005]$.

Finally, we assessed the relationship between religious coping, trust/mistrust in God, intrinsic religiosity, and impact related to COVID-19. Results are reported in Table 2 and indicate that religious variables were generally significantly and moderately related to various COVID-19 impact items. Specifically, higher intrinsic religiosity was somewhat correlated with less reported negative impact of COVID-19 on the domains of sleep, family, religious observance, and enjoying life, and moderately correlated with greater positive impact of COVID-19. Positive religious coping was somewhat correlated with less negative impact on emotions and life enjoyment, and moderately correlated with greater positive impact. Trust in God emerged as 
Table 2 Correlations between impact of COVID and religiosity

\begin{tabular}{llllll}
\hline & Intrinsic religiosity & $\begin{array}{l}\text { Positive } \\
\text { religious } \\
\text { coping }\end{array}$ & $\begin{array}{l}\text { Negative } \\
\text { religious } \\
\text { coping }\end{array}$ & Trust in God & Mistrust in God \\
\hline Sleep & $-.10^{*}$ & -.08 & $.30^{* * *}$ & $-.13^{* *}$ & $.17^{* * *}$ \\
Diet & -.07 & -.04 & $.25^{* * *}$ & $-.16^{* * *}$ & $.18^{* * *}$ \\
Fitness & -.05 & -.004 & $.14^{* *}$ & -.04 & .03 \\
Work & .02 & -.06 & .06 & -.05 & $.11^{*}$ \\
Finances & .04 & .03 & .004 & .006 & .07 \\
Family & $-.10^{*}$ & -.07 & $.18^{* * *}$ & $-.15^{* *}$ & $.17^{* * *}$ \\
Relationships & -.05 & -.04 & $.21^{* * *}$ & -.10 & $.21^{* * *}$ \\
Religious observance & $-.14 * *$ & -.05 & $.17^{* * *}$ & $-.15^{* *}$ & $.19^{* * *}$ \\
Faith in God & -.07 & -.02 & $.25^{* * *}$ & -.06 & $.16^{* * *}$ \\
Character & -.05 & -.07 & $.31^{* * *}$ & $-.10^{*}$ & $.27^{* * *}$ \\
Strong emotions & -.07 & $-.12^{*}$ & $.34^{* * *}$ & $-.14^{* *}$ & $.27^{* * *}$ \\
Enjoying my life & $-.14 * *$ & $-.10^{*}$ & $.32^{* * *}$ & $-.20^{* * *}$ & $.29 * * *$ \\
Positive impact & $.23 * * *$ & $.31^{* * *}$ & $-.15^{* * *}$ & $.29 * * *$ & $-.22^{* * *}$ \\
\hline
\end{tabular}

$* p<.05 ; * * p<.01 ; * * * p<.001$

an even more powerful correlate; it was moderately correlated with less negative impact in regard to sleep, diet, family, religious observance, character, strong emotions, enjoying life, and moderately correlated with higher positive impact. We also observed that higher levels of negative religious coping and mistrust in God correlated strongly with higher levels of negative impact in virtually all domains.

\section{Discussion}

This study examined the prevalence of primary and secondary exposure and negative/positive impact of COVID-19 among American Orthodox Jews, as well as demographic and religious predictors. While we observed a high amount of exposure and concern about exposure overall as well as high levels of compliance with medical/governmental guidelines (e.g., social distancing), levels of stress and negative impact were generally low. Moreover, we found strong evidence for positive impact of the pandemic. These findings may attest to general human resilience in the face of trauma (Bonanno 2004), and they align with the literature on posttraumatic growth (Calhoun and Tedeschi 2014). However, given consistent and strong links between distress and religious variables in our study, these low levels of distress may reflect be unique resilience related to religious coping (Gerber et al. 2011). Further, given the family and community-centric culture of Orthodox Judaism and large family sizes of participants in our study, this may suggest that there are protective benefits under quarantine to belonging to a religious family or community (Walsh 2007). 
Specifically, we found that positive religious coping, intrinsic religiosity and trust in God emerged as strong correlates of less stress and increased positive impact. As previous research suggests (Hood et al. 2018), these findings may be particularly strong among individuals with a strong religious group identity, such as Orthodox Jews, as any turn to faith also engages sense of group belonging (Aten et al. 2019). By contrast, fear of exposure to COVID-19 was related to negative coping and mistrust of God, and negative religious coping and mistrust in God correlated with increased stress and less positive impact. These findings underscore that certain facets of religion, particularly spiritual struggles, may be a risk factor for anxiety and stress. Though our cross-sectional design cannot shed light on causality, our previous work has shown that difficulties with religious coping precede emotional concerns, and not the other way around (Pirutinsky et al. 2011). Taken in aggregate, these findings highlight that certain facets of religion can have a key impact on adjustment, especially in times of crisis, as previous research has suggested (e.g., Aten et al. 2019; Davis et al. 2019a, b).

We also found that direct exposure to COVID-19 was correlated with higher levels of religiosity. While this may suggest that religion is a risk factor for greater likelihood of contracting COVID-19, we found high levels of compliance with governmental and medical guidelines in our sample of American Orthodox Jews with 87\% reporting adhering "very much" and less than $1 \%$ "not very much" or "not at all." Thus, these findings may suggest that exposure to COVID-19 may have activated the religious domain to serve as a coping method to this stressor. Along these lines, it is notable that participants reported that COVID-19 had significantly more impact on general well-being (e.g., family, work) and less impact on spiritual factors such as faith, character, and religious observance. This parallels findings outside of the Orthodox community as a national poll pf the US taken April 20th-26th, 2020 found that $24 \%$ of respondents ( $34 \%$ of religious individuals) reported that their faith had become stronger because of the coronavirus pandemic, and only $2 \%$ of respondents ( $2.7 \%$ of religious individuals) reported that their faith was weaker (Pew Research Center 2020). In aggregate, these results support the consistent line of findings that religious individuals turn to God when they experience troubling times (Hood et al. 2018) and the idea that religion proffers the most benefit for mental health under conditions of high distress (Granqvist 2020).

Beyond activating religiosity, our finding suggests that utilizing positive religious coping during the pandemic can provide mental health benefits and that spiritual struggles may harm mental health. Of note, religiosity in this study included three specific religious variables - intrinsic religiosity, religious coping, and trust in God-all of which have previously been identified as linked with coping, stress, and mental health. Intrinsic religiosity involves the sincere and intentional integration of religion into one's life (Koenig and Büssing 2010), and this integration likely provides a preexisting source of resiliency that can be drawn on in times of uncertainty and stress like COVID-19. Trust in God comprises relinquishing control over ones circumstance and believing that an omniscient God has benevolent ultimate intentions, which facilitates helpful cognitive beliefs such as "silver linings" reappraisals, tolerance of uncertainty, and a sense of meaning or purpose (Rosmarin et al. 2011a), as a secure emotional attachment (Pirutinsky et al. 2019). Religious coping includes 
positive beliefs, religious and spiritual activities, and religious social support all of which have been shown to modulate distress and relate with better mental health (e.g., Pargament et al. 1998).

Beyond these primary findings, there were several other correlations of interest. For example, while fear of possible exposure was associated with less favorable outcomes, this was not true of actual exposure to COVID-19. This highlights the influence of internal psychological coping mechanisms over external situational factors, which is the premise of many theoretical accounts of fear responding (Presti et al. 2020). As well, a number of demographic variables were associated with coping factors. For example, Orthodox women reported that pandemic had more effect on domains of life routine but not their religiosity, while the pattern was reversed for men. Gender differences in the effect of religiosity on mental health have been generally understudied (cf. Cherniak et al. 2020b), and this may be the result of the different religious and sociocultural norms associated with Orthodox Jewish religiosity for men and women, which delineate more public religious practice for men and more private religious practice for women (Schnall 2006). A third interesting finding is that while family size was associated with elevated work stress, it was also associated with enjoying life and finding positive impact of the pandemic period. Though prior studies have reported generally mixed findings (Angrist et al. 2010), our results add to the body of work suggesting that the resilience-promoting properties of large families within the Orthodox community may outweigh related stressors (e.g., Pirutinsky et al. 2015).

This study is limited by its cross-sectional design, which does not allow causal conclusions, as well as use of self-reports and not observational or direct data. Also, given the length of the questionnaire, we administered measures from a limited and somewhat overlapping selection of religious domains and did not examine or compare non-religious forms of coping or pro-social behavior, which both indicate and facilitate better coping with stressors in a disaster context (Rodriguez et al. 2006). Lastly, our sample was a self-selecting sample of Orthodox Jews, who may or may not be representative of the entire Orthodox Jewish population. Nevertheless, our findings highlight that for some, family and faith may serve as key factors in promoting resilience, especially during times of crisis.

\section{Compliance with Ethical Standards}

Conflict of interest The authors declare that they have no conflict of interest.

\section{References}

Angrist, J., Lavy, V., \& Schlosser, A. (2010). Multiple experiments for the causal link between the quantity and quality of children. Journal of Labor Economics, 28(4), 773-824.

Ano, G. G., \& Vasconcelles, E. B. (2005). Religious coping and psychological adjustment to stress: A meta-analysis. Journal of Clinical Psychology, 61(4), 461-480.

Armitage, R., \& Nellums, L. B. (2020). COVID-19 and the consequences of isolating the elderly. The Lancet. https://doi.org/10.1016/S2468-2667(20)30061-X. 
Aten, J. D., Smith, W. R., Davis, E. B., Van Tongeren, D. R., Hook, J. N., Davis, D. E., et al. (2019). The psychological study of religion and spirituality in a disaster context: A systematic review. Psychological Trauma: Theory, Research, Practice, and Policy., 11(6), 597-613. https://doi.org/10.1037/ tra0000431.

Baker, M., \& Gorsuch, R. (1982). Trait anxiety and intrinsic-extrinsic religiousness. Journal for the Scientific Study of Religion, 21(2), 119-122. https://doi.org/10.2307/1385497.

Bentzen, J. S. (2019). Acts of God? Religiosity and natural disasters across subnational world districts. The Economic Journal, 129(622), 2295-2321.

Bentzen, J. S. (2020). In crisis, we pray: Religiosity and the COVID-19 pandemic. Working paper.

Bonanno, G. A. (2004). Loss, trauma, and human resilience: Have we underestimated the human capacity to thrive after extremely aversive events? American Psychologist, 59(1), 20-28.

Calhoun, L. G., \& Tedeschi, R. G. (Eds.). (2014). Handbook of posttraumatic growth: Research and practice. London: Routledge.

Centers for Disease Control. (2020). Cases of coronavirus disease (COVID-19) in the U.S. Retrieved from https://www.cdc.gov/coronavirus/2019-ncov/cases-updates/cases-in-us.html, 22 Apr 2020.

Cherniak, A. D., Granqvist, P., Mikulincer, M., \& Shaver, P. R. (2020a). An attachment theory perspective of religion/spirituality. Current Opinions in Psychology. https://doi.org/10.1016/B978-0-12817204-9.00014-7.

Cherniak, A. D., Pirutinsky, S., \& Rosmarin, D. H. (2020). Does gender moderate effects of religion on mental health? An evaluation in a Jewish community sample [Manuscript in preparation].

Davis, E. B., Kimball, C. N., Aten, J. D., Andrews, B., Van Tongeren, D. R., Hook, J. N., et al. (2019a). Religious meaning making and attachment in a disaster context: A longitudinal qualitative study of flood survivors. The Journal of Positive Psychology, 14(5), 659-671.

Davis, E. B., Kimball, C. N., Aten, J. D., Hamilton, C., Andrews, B., Lemke, A., et al. (2019b). Faith in the wake of disaster: A longitudinal qualitative study of religious attachment following a catastrophic flood. Psychological trauma: theory, research, practice, and policy, 11(6), 578-587.

Desai, K. M., \& Pargament, K. I. (2015). Predictors of growth and decline following spiritual struggles. The International Journal for the Psychology of Religion, 25(1), 42-56.

Exline, J. J., \& Rose, E. (2013). Religious and spiritual struggles. Handbook of the psychology of religion and spirituality (2nd ed., pp. 379-398). New York, NY: Guilford Press.

Gerber, M. M., Boals, A., \& Schuettler, D. (2011). The unique contributions of positive and negative religious coping to posttraumatic growth and PTSD. Psychology of Religion and Spirituality, 3(4), 298-307.

Granqvist, P. (2020). Attachment in religion and spirituality: A wider view. New York, NY: Guilford Press.

Hack, J. (2007). Taming technology: Ultra-Orthodox Jewish families and their domestication of the internet. Retrieved August 11, 2008.

Hackney, C. H., \& Sanders, G. S. (2003). Religiosity and mental health: A meta-analysis of recent studies. Journal for the scientific study of religion, 42(1), 43-55.

Heilman, S. C. (2000). Defenders of the faith: Inside ultra-orthodox Jewry. Berkeley, CA: University of California Press.

Heller, J. (2020). Coronavirus crisis stoking anti-Semitism worldwide: Report. Reuters. https://www.reute rs.com/article/us-health-coronavirus-israel-antisemitis/coronavirus-crisis-stoking-anti-semitismworldwide-report-idUSKBN22219C.

Henrich, J., Bauer, M., Cassar, A., Chytilová, J., \& Purzycki, B. G. (2019). War increases religiosity. Nature Human Behaviour, 3(2), 129-135.

Ho, C. S., Chee, C. Y., \& Ho, R. C. (2020). Mental health strategies to combat the psychological impact of COVID-19 beyond paranoia and panic. Annals of the Academy of Medicine, Singapore, 49(1), $1-3$.

Hood, R. W., Jr., Hill, P. C., \& Spilka, B. (2018). The psychology of religion: An empirical approach. New York: Guilford Publications.

Jenkins, R. A., \& Pargament, K. I. (1995). Religion and spirituality as resources for coping with cancer. Journal of Psychosocial Oncology, 13(1-2), 51-74.

Johns Hopkins University and Medicine. (2020). Cumulative cases by date [Infographic]. Johns Hopkins University and Medicine Coronavirus Resource Center. https://coronavirus.jhu.edu/data/cumulative -cases.

Kantor Center for the Study of Contemporary European Jewry. (2020). Antisemitism world-wide. Tel Aviv: Tel Aviv University. 
Koenig, H. G. (2018). Religion and mental health: Research and clinical applications. London: Academic Press.

Koenig, H. G., \& Büssing, A. (2010). The Duke University Religion Index (DUREL): A five-item measure for use in epidemiological studies. Religions, 1, 78-85.

Koenig, H., King, D., \& Carson, V. B. (2012). Handbook of Religion and Health. Oxford: Oxford University Press.

Koenig, H. G., Pargament, K. I., \& Nielsen, J. (1998). Religious coping and health status in medically ill hospitalized older adults. The Journal of Nervous and Mental Disease, 186(9), 513-521.

Li, Z., Ge, J., Yang, M., Feng, J., Qiao, M., Jiang, R., et al. (2020). Vicarious traumatization in the general public, members, and non-members of medical teams aiding in COVID-19 control. Brain, Behavior, and Immunity. https://doi.org/10.1016/j.bbi.2020.03.007.

Lim, C., \& Putnam, R. D. (2010). Religion, social networks, and life satisfaction. American Sociological Review, 75(6), 914-933.

McBride, O., Murphy, J., Shevlin, M., Gibson Miller, J., Hartman, T. K., Hyland, P., Jiang, R., \& Bentall, R. (2020). Monitoring the psychological impact of the COVID-19 pandemic in the general population: An overview of the context, design and conduct of the COVID-19 Psychological Research Consortium (C19PRC) Study. https://doi.org/10.31234/osf.io/wxe2n.

McCullough, M. E., \& Willoughby, B. L. (2009). Religion, self-regulation, and self-control: Associations, explanations, and implications. Psychological Bulletin, 135(1), 69-93.

Pargament, K. I. (2001). The psychology of religion and coping: Theory, research, practice. New York, NY: Guilford Press.

Pargament, K. I., Smith, B. W., Koenig, H. G., \& Perez, L. (1998). Patterns of positive and negative religious coping with major life stressors. Journal for the Scientific Study of Religion, 37, $710-724$.

Pearson, J. A., \& Geronimus, A. T. (2011). Race/ethnicity, socioeconomic characteristics, coethnic social ties, and health: Evidence from the national Jewish population survey. American Journal of Public Health, 101(7), 1314-1321.

Pew Research Center. (2013). A portrait of Jewish Americans. Findings from a Pew Research Center survey of U.S. Jews. Washington, D.C. Retrieved from http://www.pewforum.org/2013/10/01/ jewish-american-beliefs-attitudes-culture-survey.

Pew Research Center. (2020). Few Americans say their house of worship is open, but a quarter say their faith has grown amid pandemic. Washington, D.C. Retrieved from https://www.pewresearc h.org/fact-tank/2020/04/30/few-americans-say-their-house-of-worship-is-open-but-a-quarter-saytheir-religious-faith-has-grown-amid-pandemic/.

Pirutinsky, S., \& Rosmarin, D. H. (2018). Protective and harmful effects of religious practice on depression among Jewish individuals with mood disorders. Clinical Psychological Science, 6, 601-609.

Pirutinsky, S., Rosmarin, D. H., \& Kirkpatrick, L. A. (2019). Is attachment to God a unique predictor of mental health? Test in a Jewish sample. International Journal for the Psychology of Religion, 29, $1-11$.

Pirutinsky, S., Rosmarin, D. H., Pargament, K. I., \& Midlarsky, E. (2011). Does negative religious coping accompany, precede, or follow depression among Orthodox Jews? Journal of Affective Disorders, 132(3), 401-405.

Pirutinsky, S., Schechter, I., Kor, A., \& Rosmarin, D. (2015). Family size and psychological functioning in the Orthodox Jewish community. Mental Health, Religion and Culture, 18(3), 218-230.

Presti, G., Mchugh, L., Gloster, A., Karekla, M., \& Hayes, S. C. (2020). The dynamics of fear at the time of COVID-19: A contextual behavioral science perspective. Clinical Neuropsychiatry, 17(2), 65-71.

Qiu, J., Shen, B., Zhao, M., Wang, Z., Xie, B., \& Xu, Y. (2020). A nationwide survey of psychological distress among Chinese people in the COVID-19 epidemic: implications and policy recommendations. General Psychiatry, 33(2), e100213.

Rodriguez, H., Trainor, J., \& Quarantelli, E. L. (2006). Rising to the challenges of a catastrophe: The emergent and prosocial behavior following Hurricane Katrina. The Annals of the American Academy of Political and Social Science, 604(1), 82-101.

Rosmarin, D. H., \& Koenig, H. G. (2020). Handbook of spirituality, religion, and mental health (2nd ed.). London: Academic Press.

Rosmarin, D. H., Pargament, K. I., Krumrei, E. J., \& Flannelly, K. J. (2009a). Religious coping among Jews: Development and initial validation of the JCOPE. Journal of Clinical Psychology, 65, $670-683$. 
Rosmarin, D. H., Pargament, K. I., \& Mahoney, A. (2009b). The role of religiousness in anxiety, depression, and happiness in a Jewish community sample: A preliminary investigation. Mental Health, Religion and Culture, 12(2), 97-113.

Rosmarin, D. H., Pirutinsky, S., Auerbach, R. P., Björgvinsson, T., Bigda-Peyton, J., Andersson, G., et al. (2011a). Incorporating spiritual beliefs into a cognitive model of worry. Journal of Clinical Psychology, 67(7), 691-700.

Rosmarin, D. H., Pirutinsky, S., Carp, S., Appel, M., \& Kor, A. (2017). Religious coping across a spectrum of religious involvement among Jews. Psychology of Religion and Spirituality, 9(Suppl 1), S96-S104.

Rosmarin, D. H., Pirutinsky, S., \& Pargament, K. I. (2011b). A brief measure of core religious beliefs for use in psychiatric settings. The International Journal of Psychiatry in Medicine, 41, 253-261.

Schnall, E. (2006). Multicultural counseling and the Orthodox Jew. Journal of Counseling and Development, 84(3), 276-282.

Simione, L., \& Gnagnarella, C. (2020). Differences between health workers and general population in risk perception, behaviors, and psychological distress related to COVID-19 spread in Italy. https:// doi.org/10.31234/osf.io/84d2c.

Stack, L. (2020). 'Plague on a biblical scale': Hasidic families hit hard by virus. New York Times. https:// www.nytimes.com/2020/04/21/nyregion/coronavirus-jews-hasidic-ny.html?auth=login-google.

Torales, J., O'Higgins, M., Castaldelli-Maia, J. M., \& Ventriglio, A. (2020). The outbreak of COVID-19 coronavirus and its impact on global mental health. International Journal of Social Psychiatry. https ://doi.org/10.1177/0020764020915212.

Vahia, I. V., Blazer, D. G., Smith, G. S., Karp, J. F., Steffens, D. C., Forester, B. P., et al. (2020). COVID19, mental health and aging: A need for new knowledge to bridge science and service. The American Journal of Geriatric Psychiatry. https://doi.org/10.1016/j.jagp.2020.03.007.

Walsh, F. (2007). Traumatic loss and major disasters: Strengthening family and community resilience. Family Process, 46(2), 207-227.

Wang, C., Pan, R., Wan, X., Tan, Y., Xu, L., Ho, C. S., et al. (2020). Immediate psychological responses and associated factors during the initial stage of the 2019 coronavirus disease (COVID-19) epidemic among the general population in China. International Journal of Environmental Research and Public Health, 17(5), 1729.

World Health Organization. (2020). Coronavirus (COVID-19). https://covid19.who.int/.

Publisher's Note Springer Nature remains neutral with regard to jurisdictional claims in published maps and institutional affiliations. 